\title{
Textos Prescritivos da Educação Presencial e a Distância: Fonte Primeira do Estresse do Professor?
}

\author{
Anna Rachel MACHADO (PUC-SP) \\ Lília Santos ABREU-TARDELLI (PUC-SP) ${ }^{1}$
}

Resumo: Este artigo visa a contribuir para a compreensão do estresse vivido pelos professores tanto de educação presencial quanto à distância. Para isso, partimos de resultados de análises de textos prescritivos oficiais (de Educação a Distância e presencial) sobre o trabalho do professor, interpretando-os com base em conceitos centrais da Clínica da Atividade (CLOT, 1999) sobre o trabalho em geral e sobre as características das prescrições que podem levar ao estresse profissional.

Palavras-Chave: textos prescritivos; estresse; trabalho educacional.

\begin{abstract}
This paper aims at contributing to the comprehension of the factors determining the rise in teacher's stress for both face-to-face and online education. We based ourselves on the interpretations of results from analyses of official prescriptive texts (for face-to-face and online education) about the teacher's work. These data interpretations were based on the guidelines of the Activity Clinic designed by Clot (1999) about the work in general and about the characteristics of the prescriptions that can lead to the professional stress.
\end{abstract}

Key Words: prescriptive texts; stress; educational work.

Resumen: Este artículo tiene por objeto contribuir para la comprensión del estrés vivido por los profesores que actúan en la educación presencial cuanto los que actúan en sistemas de enseñanza a distancia. Para eso, se toma como punto de partida resultados de análisis de textos prescriptivos oficiales (de Educación a Distancia y presencial) sobre el

${ }^{1}$ Bolsista da CAPES, desenvolve tese de doutoramento sobre o trabalho do professor de EaD no Programa de Lingüística Aplicada e Estudos da Linguagem da PUC-SP. 
trabajo del profesor, interpretándolo con base en conceptos centrales de la "Clínica de la actividad" (CLOT, 1999) sobre el trabajo en general y sobre las características de las prescripciones que pueden llevar al estrés profesional.

Palabras-Clave: textos prescriptivos; estrés; trabajo educacional.

$L$ 'analyse du travail vise toujours, en quelque façon, à comprendre our transformer.

Yves Clot, 1999

\section{Introdução}

Este artigo inscreve-se no quadro de um projeto de pesquisa mais amplo, ${ }^{2}$ cujo objetivo maior é o de investigar as relações entre a linguagem e o trabalho educacional, envolvendo análises de diferentes atividades desenvolvidas pelos professores e análises de textos produzidos sobre esse trabalho. Alguns dos textos que temos analisado são os que são produzidos por instituições governamentais, que buscam orientar e/ou prescrever as tarefas dos professores e que têm sido chamados de "textos prescritivos do trabalho educacional", utilizandose expressão consagrada pela ergonomia em relação a outras situações de trabalho.

A necessidade desse tipo de estudos tem sido salientada por vários pesquisadores da área, como Amigues (2003), que observa que a questão das prescrições tem estado ausente das pesquisas sobre o ensino ou sobre o 'funcionamento' do professor, como se elas não influíssem a ação de ensinar, apesar de ser conhecido o fato de que elas determinam, pelo menos em parte, a sua realização. Amigues (2003) ainda afirma que, ao contrário do que ocorre em outros domínios de atividade profissional, as prescrições para o trabalho do professor são bastante vagas e imprecisas, o que é também ressaltado por Faïta (2003). Saujat (2002), do mesmo modo, ressalta essa insuficiência, considerando que a análise de textos que veiculam as prescrições do trabalho deve ser um elemento essencial para a apreensão das propriedades do trabalho educativo.

\footnotetext{
${ }^{2}$ Esse projeto está sendo desenvolvido pelo Grupo ALTER (LAEL-PUC-SP), que envolve vários mestrandos e doutorandos.
} 
Assim, para nós, os objetivos centrais das análises desse tipo de textos têm sido os seguintes:

a) investigar quais são as características genéricas, textuais e enunciativas próprias desses textos;

b) identificar a forma como se configuram as tarefas que são atribuídas aos professores, isto é, que tipo de agir lhes é prescrito e quais são os aspectos desse agir que neles são tematizados. Esse objetivo pode ser melhor compreendido, atentando-se para uma série de questões que permitem sua operacionalização, tais como: Quais são os elementos do trabalho docente que são tematizados? (seus conhecimentos, suas competências, suas atitudes, o papel e os conhecimentos, competências e atitudes dos alunos?) Qual é o grau de generalidade ou de especificidade com que são elencadas as tarefas prescritas aos professores? Que tipo de responsabilidade é atribuída aos professores? Para desenvolver que tipo de processos?

Acreditamos que respostas a questões como essas poderão contribuir para a clarificação das concepções sobre o estatuto do trabalho do professor e sobre o papel que lhe é atribuído nos diferentes textos que sobre ele são produzidos. Assim, guiadas por esses objetivos e pelos procedimentos de análise descritos em Bronckart \& Machado (2004), as autoras deste artigo já desenvolveram análises sobre textos prescritivos voltados para o trabalho do professor tanto no ensino presencial (BRONCKART; MACHADO, 2004) quanto à distância (ABREU-TARDELLI, 2004). Alguns desses textos analisados são, de um lado, a carta do Ministro da Educação introdutória aos Parâmetros Curriculares Nacionais para o Ensino Médio (BRASIL, 1998b) e segmentos sobre metodologia retirados dos Parâmetros para o Ensino de Ciências (BRASIL, 1998b) e, de outro, o Decreto nº. 2.494 de 10 de fevereiro de 1998 (BRASIL, 1998a), que regulamenta o artigo 80 da Lei $n^{\circ}$ 9.394, de 20 de dezembro de 1996, primeira lei sobre a Educação a Distância no Brasil.

Neste artigo, buscamos avançar em nossa discussão sobre os textos prescritivos, de forma particular no que diz respeito à sua 
influência sobre o estresse vivido pelos profissionais da educação, perguntando-nos até que ponto as próprias prescrições não contribuem para a instalação e/ou manutenção desse problema. Para isso, em primeiro lugar, apresentaremos considerações sobre o estresse do professor e concepções da chamada Clínica da Atividade sobre o trabalho em geral (CLOT, 1999) e ainda sobre as características das prescrições que podem levar ao estresse profissional. A partir daí, levantaremos questões sobre as características das prescrições ao trabalho do professor, selecionando, para ser discutida neste artigo, a questão do papel que nelas é atribuído ao professor. A seguir, retomaremos, resumidamente, algumas de nossas análises referentes a essa questão, relacionando-as às considerações de Clot para chegarmos às conclusões finais.

Queremos deixar claro que nosso objetivo maior é o de estimular outros pesquisadores a desenvolverem pesquisas que nos levem a uma compreensão mais aprofundada dos fatores que levam ao estresse profissional, a fim de podermos contribuir para sua superação ou, pelo menos, para sua minimização $\left.{ }^{3}\right) .{ }^{4}$

\section{O Estresse do Trabalhador, a Atividade de Trabalho e as Prescrições}

A escolha do problema do estresse do profissional da educação para nossa reflexão pode ser atribuída a dois fatores conjugados. Em primeiro lugar, ao fato de que já não é de agora que vários pesquisadores têm detectado, como fenômenos internacionais

\footnotetext{
${ }^{3}$ Discussão essa que também é retomada em outros artigos desta revista, por pesquisadores envolvidos em nosso projeto mais amplo.

${ }^{4}$ Vale ressaltar que as motivações e o aprofundamento das pesquisas aqui apresentadas foram paulatinamente sendo fortalecidos no decorrer dos três últimos anos, em discussões efetivadas com três grupos de pesquisadores: Grupo ALTER, da PUC-SP (Machado, 2004), ao qual pertencemos, Grupo Langage-Action-Formation (LAF), da Universidade de Genebra 4 (BRONCKART, 2004), e Grupo Ergonomie de l'Activité des Professionnels de l'Education (ERGAPE), do Instituto de Formação de Professores de Marselha e mais recentemente, com o pesquisador do CNAM, Prof. Dr. Yves Clot (1999).
} 
da educação contemporânea, um certo "mal-estar docente", acompanhado de uma crise de identidade profissional dos professores (ESTEVE, 1999). De acordo com Machado \& Magalhães (2002), o ensino tem sido submetido a uma crítica social contínua e levado à desvalorização do papel social do professor e à culpabilização do professor pelo chamado "fracasso escolar", -considerando-se problemas que, na verdade, são de ordem social, como sendo da pura esfera individual. Em segundo lugar, a escolha desse tema inspira-se em uma concepção da atividade de trabalho da chamada Clínica da Atividade (CLOT, 1999), que nos auxilia a compreender melhor, de um ponto de vista psicossocial e vygotskyano, a relação entre as prescrições e o estresse dos profissionais em geral.

Para Clot (1999), a questão desse estresse deveria ser vista de um ponto de vista exatamente contrário ao que é usualmente difundido pelos discursos oficiais e dominantes: para o autor, não seria o trabalhador que não está conseguindo atender às exigências das instituições e da sociedade em geral, mas sim, seriam essas mesmas instituições que não estariam atendendo às reais necessidades dos trabalhadores, não os ouvindo e nem reconhecendo sua real contribuição. Justificando sua posição, o autor concebe o trabalho como uma atividade que é sempre mediada por instrumentos e dirigida a três pólos - ao objeto, ao próprio sujeito e a outrem. Por definição, ela é sempre conflituosa, envolvendo conflitos diversos: conflitos do sujeito consigo mesmo (por exemplo, entre o que pode fazer e o que gostaria de fazer, entre as diferentes escolhas que pode fazer), conflitos entre o sujeito e o objeto sobre o qual a atividade é exercida e conflitos entre o sujeito e um "outrem", compreendendo-se esse outrem como qualquer outro indivíduo que possa interferir na atividade, que pode estar presente no curso da atividade ou "no próprio sujeito".

Além disso, para que o trabalhador possa realizar sua atividade, o meio social disponibiliza para ele o que podemos chamar de "artefatos" sócio-historicamente constituídos, tanto de ordem material (um martelo, por exemplo) quanto de ordem simbólica, incluindo-se aí as próprias prescrições orais ou escritas. Entretanto, esses artefatos só poderiam se constituir como verdadeiros "instrumentos" para o trabalhador, quando ele os considera realmente úteis, deles se apropriando, "por si e para si". Assim, por exemplo, o 
martelo só será um verdadeiro instrumento, se o sujeito souber usá-lo adequadamente para um determinado fim; da mesma forma, uma prescrição de como utilizar um determinado material didático, ou ainda, uma determinada ferramenta de cursos online (chat educacional, fórum, dentre outros) só será um verdadeiro instrumento, se o sujeito, de fato, se apropriar dele.

Artefatos que podem ser considerados extremamente úteis para a resolução dos conflitos da atividade seriam os chamados "gêneros da atividade", conjunto de regras explícitas ou implícitas para o agir, construídas pelo próprio coletivo de trabalho, pelo próprio conjunto de trabalhadores de uma determinada profissão, ausentes ou presentes. Esse conjunto indica as formas de fazer, sentir e agir em um determinado ofício, "sancionadas" pelo coletivo de trabalho no decorrer de sua história para a resolução dos conflitos próprios de um determinado 'métier'.

Entretanto, é necessário ressaltar que o que está sendo aqui chamado de "conflito", para Clot (1999) pode ter conseqüências positivas ou negativas no desenvolvimento do sujeito e de sua atividade. De um lado, o conflito pode se constituir em fonte vital para o desenvolvimento e, de outro, pode deixar o trabalhador diante de dilemas intransponíveis, chegando a impossibilitar o seu agir, o que impediria seu desenvolvimento e geraria sofrimentos mal conhecidos e às vezes denegados, ponto de partida para o estresse e a fadiga. Desse modo, para Clot (1999), o estresse e a fadiga teriam uma raiz comum: a amputação do agir possível do trabalhador, amputação essa que pode ter sua origem em qualquer um desses conflitos quando não ultrapassados.

Vejamos agora mais especificamente o que Clot afirma sobre a introdução de novas prescrições para os trabalhadores em um determinado ofício. Para o autor, essa introdução sempre afeta, de uma forma ou de outra, o gênero de atividade que caracteriza o ofício. Isso pode trazer uma perturbação grave para as regras coletivas já estabelecidas, fragilizando o gênero de atividade que guia o agir do trabalhador, deixando-o só e desamparado diante dos conflitos, principalmente quando todo o coletivo de trabalho é atingido ou quando não são criadas condições para que o coletivo, por si mesmo, introduza as mudanças necessárias em seu gênero de atividade. De acordo com Clot (1999), se as prescrições produzidas pelas instituições 
não levarem em conta o gênero de atividade que já é seguido pelos trabalhadores, isso pode levar a uma desregulação da ação individual, pois, a cada vez que esse gênero lhes falta, a própria vida psíquica pessoal de cada um é profundamente atingida. Em outras palavras, pode-se gerar um "déficit instrumental", que leva o trabalhador a um sentimento de impotência, "déficit" esse que pode advir:

- da ausência total de prescrições para o agir;

- da existência de prescrições vagas, que, de fato, não orientam o trabalho a ser realizado;

- da falta de recursos materiais ou simbólicos que possam servir efetivamente para que os objetivos a serem atingidos, de acordo com as prescrições, possam ser atingidos;

- da dificuldade no manuseio de novo(s) artefato(s) (material ou simbólico).

Além disso, quando orientadas pelas novas formas de organização de trabalho, as prescrições podem veicular uma ideologia do trabalho pela qual a responsabilidade do sucesso ou fracasso das atividades é atribuída às equipes de trabalho, e não às chefias e hierarquias, reais detentoras do controle geral. De acordo com Clot (1999), essa ideologia que coloca essa responsabilidade sobre os trabalhadores demanda que eles assumam responsabilidades, sem que, de fato, uma responsabilidade real ou os meios para exercê-la lhes sejam dados, além de poder gerar um alto grau de concorrência e de vigilância entre os próprios trabalhadores. Evidentemente, tudo isso pode ser um fator gerador de estresse.

Parece-nos que muitas dessas considerações de Clot possibilitam levantar inúmeras questões sobre o papel das prescrições educacionais oficiais. Dentre elas, podemos destacar as seguintes:

- em que medida essas instituições estariam "ouvindo" os professores e "reconhecendo sua real contribuição"? - em que medida as atividades docentes já desenvolvidas e consagradas pelo coletivo de trabalho são/foram consideradas para a produção das novas prescrições?

- em que medida os artefatos materiais ou simbólicos disponibilizados para os professores (os próprios 
Parâmetros e seus conteúdos, por um lado, e os computadores, softwares e ferramentas dentro desses softwares - chats educacionais, fóruns -- por outro) podem/poderiam ser apropriados pelos professores como reais instrumentos para a execução das tarefas que lhes são prescritas?

- em que medida foram/estão sendo disponibilizados recursos materiais e simbólicos realmente adequados para que os objetivos que são colocados nos textos prescritivos pudessem/possam ser atingidos?

- em que medida essas prescrições veicularam/veiculam a ideologia do trabalho em equipe e da atribuição da responsabilidade pelo sucesso ou fracasso do ensino exclusivamente aos trabalhadores?

- em que medida as prescrições veiculadas foram/são suficientemente claras, precisas e não vagas?

- em que medida se atribui/atribuiu uma real responsabilidade aos professores nas prescrições veiculadas pelos textos?

Todas essas questões mereceriam várias pesquisas de campo e de análise de vários tipos de textos para serem respondidas adequadamente. Neste artigo, centrar-nos-emos na última, dado que os resultados de nossas análises, que incidem sobre a configuração (ou as figuras projetadas) que se esboça do agir do professor a partir desses documentos, permitem encaminhar algumas respostas a ela.

\section{As Figuras Projetadas Sobre o Trabalho do Professor nos Textos Prescritivos Analisados}

Para respondermos à questão mencionada acima, em primeiro lugar, assumimos uma série de conceitos de uma semântica do agir em construção (BRONCKART; MACHADO, 2004, p. 154156), cujos termos centrais definimos a seguir. Para nós, o agir humano nunca é diretamente observável, sendo as noções de ação, atividade, agente etc., um produto de nossas interpretações sobre as condutas diretamente observáveis, interpretações essas que podem ser expressas 
em textos orais ou escritos. Assim, para investigar essas "figuras interpretativas do agir", desenhadas nos textos, tomamos a seguinte rede conceitual: nos textos sobre um agir em que se prefigura/prescreve um determinado tipo de agir, quando se trata de trabalho, este pode aparecer decomposto em várias tarefas verbais ou não verbais, que podem se apresentar na forma de cadeias de processos constituídos por atos verbais e não verbais. No plano motivacional do agir, podem aparecer referências aos determinantes externos do trabalho a ser realizado, quando as razões para o agir são atribuídas a instâncias coletivas, e/ou a motivos, quando as razões para o agir são atribuídas a uma pessoa particular. No plano da intencionalidade, pode haver referências às finalidades, quando essa intencionalidade é atribuída a um coletivo, e/ou às intenções, que são razões para o agir atribuídas a uma pessoa particular. No plano dos recursos para o agir, pode haver referências aos artefatos materiais ou simbólicos disponibilizados pelo meio social e/ou às capacidades ou recursos mentais ou comportamentais que são atribuídas a uma pessoa particular. Em relação aos seres humanos envolvidos no agir, pode haver menção a vários actantes, isto é, a qualquer pessoa implicada no agir (ou para qualquer elemento não humano que é elevado a essa categoria no texto analisado). Esses actantes só serão considerados por nós como sendo construídos no texto como verdadeiros atores, quando são representados pelas formas textuais como sendo a fonte de um processo, com capacidades, motivos e intenções próprias e, portanto, com responsabilidade real nos processos prescritos, ou como meros agentes, quando essas mesmas formas não lhes atribuem essas propriedades e essa responsabilidade.

Ao adotarmos essa rede conceitual, foi necessário encontrarmos procedimentos de análise válidos, com apoio lingüístico, que nos permitissem identificar esses elementos do agir representado nos textos de forma mais consistente do que por meio de uma leitura ingênua. Para isso, dois tipos de procedimentos foram desenvolvidos: a identificação das unidades temáticas centrais que indicam os protagonistas centrais que são colocados em cena no texto e os papéis sintático-semânticos que lhes são atribuídos. Para isso, utilizamos os seguintes procedimentos:

a) identificação e classificação dos tipos de frases do ponto de vista sintático, distinguindo entre frases 
principais e subordinadas, frases com voz ativa (ou neutra) e com voz passiva; frases com verbo conjugado ou com infinitivo;

b) identificação dos sintagmas nominais que aparecem em função de sujeito ou complemento verbal;

c) identificação da função sintático-semântica desses sujeitos e complementos, de acordo com uma classificação inspirada em Fillmore (1975): agentivo responsável animado por um processo dinâmico; atributivo (ou experenciador) - destinatário da atribuição de um processo de estado; objetivo - objeto de um processo dinâmico, que prolonga o semantismo verbal; beneficiário -destinatário animado de um processo dinâmico; instrumental -elemento inanimado que contribui para a realização de um processo dinâmico ou que é uma causa imediata;

d) relacionamento dessas funções aos conceitos da semântica do agir adotada;

e) identificação e análise dos lexemas (verbos) que denotam processos do agir que é prescrito e dos protagonistas que são colocados como seus responsáveis.

Para exemplificar as categorias acima, o Artigo $2^{\circ} \ 3^{\circ}$ do decreto poderia ser assim analisado:

Artigo $2^{\circ} \int 3^{\circ}-A$ autorização, o reconbecimento de cursos e o credenciamento de instituições do sistema federal de ensino que ofereçam cursos de educação profissional a distância deverão observar, além do que estabelece este Decreto, o que dispõe as normas contidas em legislação específica. 


\begin{tabular}{|l|l|l|l|l|}
\hline \multicolumn{1}{|c|}{ Protagonistas } & $\begin{array}{c}\text { Função } \\
\text { sintática }\end{array}$ & $\begin{array}{c}\text { Função } \\
\text { semântica }\end{array}$ & $\begin{array}{c}\text { Tipo de } \\
\text { frase }\end{array}$ & Verbo \\
\hline $\begin{array}{l}\text { A autorização, o } \\
\text { reconhecimento } \\
\text { de cursos e o }\end{array}$ & Sujeito & Instrumental & $\begin{array}{l}\text { Subordina } \\
\text { da Ativa }\end{array}$ & Ofereçam \\
$\begin{array}{l}\text { credenciamento } \\
\text { de instituições }\end{array}$ & Sujeito & Atributivo & Ativa & $\begin{array}{l}\text { Deverão } \\
\text { observar }\end{array}$ \\
\hline
\end{tabular}

Assim, com a análise do decreto analisado, pudemos verificar que é a partir de uma definição de $\mathrm{EaD}^{5}$ que se segue a enumeração de uma série de atos a serem desenvolvidos, mas não por sujeitos humanos e sim, pelos cursos ou pelas instituições. Os demais artigos do decreto irão confirmar o que se encontra desde o primeiro, revelando que os atos previstos pelo decreto não constituem um agir que seja da responsabilidade do professor. Verificamos que são os cursos e as instituições - "objetos" inanimados - que são tratados como protagonistas centrais do agir, ao mesmo tempo em que é atribuída à Educação a Distância o estatuto de um "ensino" que possibilitaria mesmo a auto-aprendizagem. Assim, não há espaço nesse decreto para a inserção do trabalho do professor, que se encontra totalmente ausente. ${ }^{6}$ A negação a seu trabalho já aparece desde o primeiro artigo e, apesar de o aluno aparecer no decreto como sendo o sujeito avaliado, não se sabe quem irá avaliá-lo e se o professor estará envolvido nesse processo.

Em relação à análise da mensagem do Ministro da Educação que inicia os PCNs, -pudemos detectar que cinco protagonistas centrais estão implicados e/ou visados pela prescrição: o próprio Ministro-autor, a demanda social, os documentos dos PCNs, os professores e os jovens. Quanto aos professores, só os que participaram

\footnotetext{
5 “Artigo $1^{\circ}$ - Educação a distância é uma forma de ensino que possibilita a autoaprendizagem, com a mediação de recursos didáticos sistematicamente organizados, apresentados em diferentes suportes de informação, utilizados isoladamente ou combinados, e veiculados pelos diversos meios de comunicação".

${ }^{6}$ Sobre a correção dessa definição feita pelo parecer CNE 41/2002, ver análise em Abreu-Tardelli (2004).
} 
da produção da prescrição é que são construídos pelo texto como reais atores. Os professores-destinatários são colocados no papel de beneficiários do ato de entrega e dos efeitos dos documentos. $\mathrm{O}$ agir prescrito futuro desses professores não é colocado como trabalho e não são mencionados os atos específicos das tarefas que deverão realizar, mas apenas as atividades genéricas a serem realizadas nas escolas a partir dos documentos (discussão, reflexão etc.).

Para confirmar essa análise, vejamos como se apresenta o trabalho do professor em segmentos em que aparece um agir mais detalhado do professor, mais especificamente, de seu trabalho na sala de aula. Nos segmentos dos PCNs de Ciências, que foram analisados para esse fim, constatamos que os protagonistas centrais colocados em cena são a metodologia proposta, os professores e os alunos. A metodologia e seus princípios aparecem como os motores centrais do processo a ser desenvolvido. Aos professores é atribuída uma responsabilidade sobre alguns dos processos a serem desenvolvidos na sala de aula, mas, em sua maioria, eles se referem à simples aplicação dos princípios metodológicos gerais e à organização das tarefas. Na verdade, são muito pouco tematizados, ou pouco precisados, os atos constitutivos das interações que julgamos se desenvolver constantemente entre o professor e os alunos, atos esses constitutivos do trabalho concreto do professor. Isso nos leva a considerar que, mesmo quando se configuram processos acionais a serem desenvolvidos pelos professores, as prescrições continuam em nível genérico e atribuem ao professor o papel de um simples aplicador da metodologia proposta.

\section{Conclusões Sobre Prescrições para a Atividade Educacional e o Estresse do Professor}

As análises realizadas nos possibilitam indicar duas questões importantes sobre os textos prescritivos analisados: ou nos encontramos diante de um total ocultamento ou negação do trabalho do professor, como é o caso do decreto, ou diante da construção de sua 'figura' como um simples adjuvante ou instrumento de um processo que se apresenta como tendo um caráter inelutável e quase que mecânico, pois bastaria que o professor aplicasse os princípios sugeridos pelas 
prescrições para que os objetivos da atividade fossem alcançados. Assim, consideramos que, nesses textos, o papel de um real ator do processo educacional é negado aos professores, pois quase nunca aparecem como actantes no pleno exercício de sua responsabilidade, dotados de motivos, intenções e capacidades próprias diante de seu trabalho.

$\mathrm{Na}$ medida em que nesses textos lhes é negado esse papel de ator e na medida em que aceitamos a consideração de Clot (1999) de que o estresse e a fadiga do trabalhador poderiam advir da 'amputação da atividade possível', podemos afirmar que o estresse e a fadiga do professor parecem começar a se delinear a partir dos próprios textos prescritivos, uma vez que consideramos que negarlhes a condição de ator constitui-se, pelo menos em parte, como uma verdadeira 'amputação' simbólica. Além disso, a multiplicação de textos como esses acabam por contribuir para a consolidação de representações sociais negativas sobre o trabalho do professor, o que pode, evidentemente, colaborar para sua desvalorização social e para a crise identitária desse profissional.

\section{Referências Bibliográficas}

ABREU-TARDELLI, Lília Santos. O trabalho do professor em EaD na lente da legislação. In: Anna Rachel Machado (org.). O ensino como trabalho: uma abordagem discursiva. Londrina: Eduel, 2004. p. 167197.

AMIGUES, René. Pour um approche ergonomique de de l'activité enseignante. Skholê, s/n. 2003. (cópia enviada pelo autor pela internet).

BRASIL. Decreto ${ }^{\circ} \mathbf{2 . 4 9 4}$, de 10 de fevereiro de 1998. Regulamenta o art. 80 da Lei $n^{\circ}$ 9.394, de 20 de dezembro de 1996, e dá outras providências. Brasília, 10 fev. 1998a. Disponível em: <http:// www.presidencia.gov.br/ccivil_03/decreto/D2494.htm>. Vários acessos.

MEC/SEF. Parâmetros Curriculares Nacionais: terceiro e quarto ciclos do ensino fundamental: introdução aos parâmetros 
curriculares nacionais. Brasília, 1998b. Disponível em: <http:// www.mec.gov.br>. Vários acessos entre 1 abr. 20031 jul. 2003.

BRONCKART, Jean-Paul. Pourquoi et comment analyser l'agir verbal et non verbal en situation de travail? Le projet de recherche du groupe Langage, Action, Formation. Les Cahiers de la Secction des Sciences de l'Education de la FAPSE, n. especial, p. 11-144, 2004.

; MACHADO, Anna Rachel. Procedimentos de análise de textos sobre o trabalho educacional. In: MACHADO, Anna Rachel Machado (Org.). O ensino como trabalho: uma abordagem discursiva. Londrina: Eduel, p. 131-163, 2004.

CLOT, Yves. La fonction psychologique du travail. Paris: PUF, 1999.

ESTEVE, J. M. O mal-estar docente: a sala de aula e a saúde dos professores. Trad. Durley de C. Cavicchia. Bauru: EDUSC, 1999.

FAÏTA, Daniel. Apport des sciences du travail à l'analyse des activités enseignantes. Documento de trabalho. 2003.

FILLMORE, C. Quelques problèmes posés à la grammaire casuelle. Langages, n. 38 , p. 65-80, 1975.

MACHADO, Anna Rachel; MAGALHÃES, Maria Cecília Camargo. A assessoria a professores na universidade brasileira: a emergência de uma situação de trabalho a ser desvelada. In: SILVA, Maria Cecília Pérez Souza; FAÏTA, Daniel (Orgs.). Linguagem e trabalho: construção de objetos de análise no Brasil e na França. São Paulo: Cortez, 2002. p. 139-156.

SAUJAT, Frédéric. Ergonomie de l'activité enseignante et développement de l'expérience professionnelle: une approche clinique du travail du professeur. 2002. Tese (Doutorado em Ciências da Educação) - Université de Aix-Marseille I, França. 